\title{
Strategies for less motion sickness on tilting trains
}

\author{
R. Persson ${ }^{1} \&$ B. Kufver ${ }^{2}$ \\ ${ }^{1}$ KTH, Sweden \\ ${ }^{2}$ Ferroplan, Sweden
}

\begin{abstract}
Many railways have put tilting trains into operation on lines with horizontal curves with small radii. Tilting trains have vehicle bodies that can roll inwards, reducing the lateral acceleration perceived by the passengers. Tilting trains can therefore run through curves at higher speeds. However, excessive tilt motions can cause motion sickness in sensitive passengers. On the other hand, too little tilting will cause discomfort from high lateral acceleration and jerk.

The present paper presents new tilt algorithms aimed at balancing the conflicting objectives of ride comfort and less motion sickness. An enhanced approach is taken, where the amount of tilt depends on the local track conditions and the train speed. The paper shows how selected tilt algorithms influence certain motion sickness related carbody motions.

Speed profiles designed to avoid local peaks in the risk of motion sickness are another possibility. The speed profiles for both tilting and non-tilting trains are today set from safety and comfort perspectives only, thus minimizing the running time. The present paper shows how speed profiles could be used to balance the conflicting objectives of running time and less risk of motion sickness. The result is derived from simulations and put in relation to today's tilt algorithms and speed profiles on the Stockholm-Gothenburg main line in Sweden $(457 \mathrm{~km})$.

Keywords: tilting train, tilt algorithm, tilt strategy, passenger comfort, motion sickness, running time simulation.
\end{abstract}




\section{Introduction}

Growing competition from other modes of transportation has forced railway companies throughout the world to search for increased performance. Travel time is the most obvious performance indicator that can be improved by introducing high-speed trains. Trains with a capability to tilt the carbodies inwards in track curves constitute a less costly alternative than building new lines with large curve radii. The idea of tilting trains on lines with curves with small radii was discussed as long ago as the 1930s [2, 3]. The inward tilt reduces the centrifugal force to which the passengers are subjected, allowing the train to pass curves at higher speed while maintaining ride comfort. Carbody tilting is today a mature and relatively inexpensive technology [4].

Experience shows that tilting trains can cause motion sickness in sensitive passengers [5-9]. The difference in risk of motion sickness between non-tilting and tilting rolling stock has attracted particular interest. Roll and vertical motions are the two carbody motion components that show the largest increase compared to non-tilting trains and are a consequence of the tilt applied [10]. However, too little tilting will cause discomfort due to high lateral acceleration and jerk. The present paper presents new tilt algorithms aimed at balancing the conflicting objectives of ride comfort and less risk of motion sickness.

Most existing tilting trains use a fixed relation between the track plane acceleration and the amount of tilt. As in [1], the present enhanced approach applies an amount of tilt commensurate with the local track conditions and speed of the train. Modified speed profiles especially designed to avoid local peaks in the risk of motion sickness are another possibility. Today's speed profiles are designed to minimize the running time taking safety and comfort parameters into consideration. The present paper shows how the risk of motion sickness could be considered when setting speed profiles.

\section{Vehicle motions}

Measured vehicle motions give important information, in particular as regards the difference between tilting and non-tilting trains. Figure 1 shows a Power Spectral Density (PSD) diagram for carbody roll acceleration; one motion component with a large increase from non-tilting to tilting trains in on-track tests [10]. A four-car long-distance tilting train, class BM73, from Norwegian State Railways (NSB) was used as the test train. The non-tilting cases were run with the same train, but with the tilt switched off and at speeds corresponding to nontilting trains. The measurements were taken on the Norwegian line between Kristiansand and Vegårdshei, a line containing numerous curves with $300 \mathrm{~m}$ radii. The main difference as regards carbody roll acceleration is found between $0.02 \mathrm{~Hz}$ and $0.5 \mathrm{~Hz}$ where the tilting train shows larger amplitudes than the nontilting one. Carbody vertical acceleration shows similar differences to carbody roll acceleration. PSD diagrams for all six motion components are shown in [10]. 


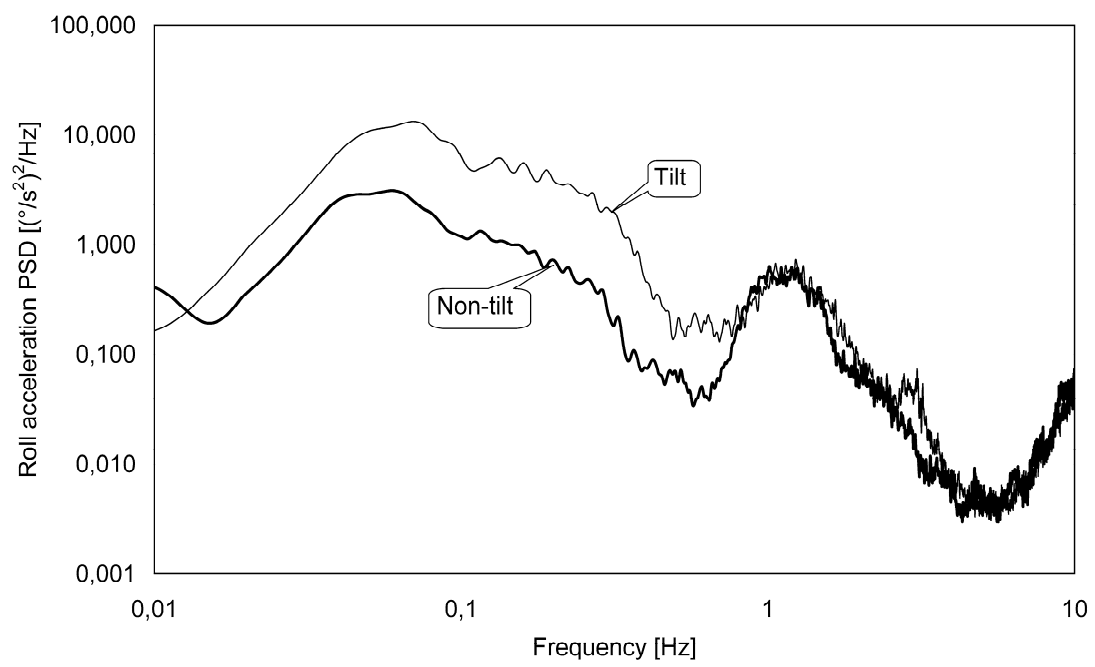

Figure 1: Power Spectral Density (PSD) for carbody roll acceleration at on-track tests between Kristiansand and Vegårdshei in Norway [10]. The non-tilting case was run with the same train, but with the tilt switched off and at speeds corresponding to non-tilting trains.

The effect of vertical and roll acceleration on motion sickness could not be adequately separated as the two motions were strongly correlated in the on-track tests.

\section{Evaluation criteria}

\subsection{Single source comfort criteria}

The requirements in respect of lateral acceleration are often set indirectly by limiting the permissible track plane acceleration. The EU-funded research project Fast and Comfortable Trains (FACT) studied the comfort-related quantities for plain track on the basis of certain European track standards [11]. For conventional trains, the results regarding lateral acceleration ranged from $0.78 \mathrm{~m} / \mathrm{s}^{2}$ to $1.41 \mathrm{~m} / \mathrm{s}^{2}$ with an average of $1.00 \mathrm{~m} / \mathrm{s}^{2}$. The corresponding results for tilting trains are lower, ranging from $0.48 \mathrm{~m} / \mathrm{s}^{2}$ to $1.00 \mathrm{~m} / \mathrm{s}^{2}$ with an average of $0.63 \mathrm{~m} / \mathrm{s}^{2}$.

Japanese Railways have used $0.80 \mathrm{~m} / \mathrm{s}^{2}$ as the limit since the 1960s [12]. This limit was challenged by [13], and [14] indicated that a more liberal limit could be applied as only $10 \%$ of the standing subjects reported discomfort at $1.0 \mathrm{~m} / \mathrm{s}^{2}$ and only $5 \%$ of the seated subjects reported discomfort at $1.2 \mathrm{~m} / \mathrm{s}^{2}$. The limit on lateral acceleration has now been relaxed to $0.90 \mathrm{~m} / \mathrm{s}^{2}$ for certain trains with seated passengers only. However, they also found that combined comfort criteria were more effective than limits on single sources (see Clause 3.2). 
Among European railways, the requirements regarding lateral jerk are set in the same indirect way as for lateral acceleration. The calculated lateral jerk for conventional trains ranged from $0.24 \mathrm{~m} / \mathrm{s}^{3}$ to $0.71 \mathrm{~m} / \mathrm{s}^{3}$ with an average of $0.48 \mathrm{~m} / \mathrm{s}^{3}$ [11]. The corresponding results for tilting trains are considerably lower, ranging from $0.15 \mathrm{~m} / \mathrm{s}^{3}$ to $0.50 \mathrm{~m} / \mathrm{s}^{3}$ with an average of $0.27 \mathrm{~m} / \mathrm{s}^{3}$.

The introduction of natural tilting trains in Japan raised motion sickness as a comfort issue. Correlation between roll motions and motion sickness was reported [9] and a limit of 5 degrees/s was set so as to avoid discomfort. Calculated carbody roll velocities for tilting trains ranged from 2.3 degrees $/ \mathrm{s}$ to 7.6 degrees/s with an average of 5.1 degrees/s when FACT studied the comfortrelated quantities for plain track on the basis of certain European track standards [11].

\subsection{Combined comfort criteria}

British Rail Research has described how to combine motion components in a curve transition to one comfort criterion [15-16]. The method differentiates between seated and standing passengers, but is here only referred to for seated passengers. The $P_{C T}$ Comfort index calculates the percentage of dissatisfied passengers on the basis of eqn (1). A reasonable acceptance value is in the interval from 3 to 7 .

$$
P_{C T}=\left\{\max \left[\left(8.97 \cdot\left|\ddot{y}_{1 s}\right|_{\max }+9.68 \cdot\left|\dddot{y}_{1 s}\right|_{\max }-5.9\right) ; 0\right]+0.12 \cdot\left(\left|\dot{\varphi}_{1 s}\right|_{\max }\right)^{1.626}\right\}
$$

where $\ddot{y}=$ Lateral acceleration in carbody $\left[\mathrm{m} / \mathrm{s}^{2}\right], \dddot{y}=$ Lateral jerk in carbody $\left[\mathrm{m} / \mathrm{s}^{3}\right]$ and $\dot{\varphi}=$ Roll velocity in carbody [degrees $\left./ \mathrm{s}\right]$.

A similar combined comfort criterion has been developed in Japan [14]. In addition, this method differs between seated and standing passengers, here given for seated passengers. The $T C_{T}$ Comfort index calculates the discomfort on a 1 to 4 scale, where 1 is not uncomfortable and 4 extremely uncomfortable, the result is expressed as eqn (2). Note that the two combined comfort criteria of lateral acceleration and jerk have approximately equal weight.

$$
T C_{T}=0.4 \cdot \ddot{y}+0.4 \cdot \dddot{y}+0.02 \cdot \dot{\varphi}+0.04 \cdot \ddot{\varphi}+0.8
$$

where parameters are as above plus $\ddot{\varphi}=$ Roll acceleration in carbody $\left[\right.$ degrees $\left./ \mathrm{s}^{2}\right]$.

\subsection{Motion sickness}

Motion sickness is not correlated to a single curve but is rather an accumulated effect from several curves. A limit on one or more motion components is presumably not generally appropriate. A model where motion doses are accumulated over time and recovery can be quantified may be a better choice [17]. Carbody vertical acceleration gave the highest correlation to motion sickness in several on-track tests [10]. However, the motion amplitudes 
measured during the test were lower than those proven to cause motion sickness during laboratory experiments. This indicates that other motion components such as roll velocity and lateral acceleration contribute to the motion sickness experienced on tilting trains.

\section{Optimization algorithms}

\subsection{General}

The approach taken in the present study is to reduce the difference in motion between non-tilting trains and tilting trains by applying just as much tilt as is necessary to avoid discomfort. This approach will minimize both carbody vertical acceleration and roll velocity at the expense of lateral acceleration and jerk. Comfort criteria must therefore be set to avoid unacceptable amplitudes on the latter ones. Three different discomfort criteria can be distinguished.

1. Lateral acceleration

2. Lateral jerk

3. Combination of lateral acceleration and jerk

The acceptance values of these criteria were discussed in Sections 3.1 and 3.2. The combination of lateral acceleration and jerk is a simplification of the combined criteria, where the roll motions have been omitted. These motions will be minimized anyhow by the general approach of applying just the amount of tilt necessary to avoid discomfort. An example of how the three comfort criteria result in an acceptance area is shown in Figure 2.

One option to fulfil the comfort criteria would be to modify the ratio between tilt angle and track plane acceleration. However, the potential of such an approach is limited as the ratio must be set large enough to fulfil the comfort criteria at the largest permissible track plane acceleration. A non-linear ratio between tilt angle and track plane acceleration would be slightly better, but the potential is also here limited by the requirement to fulfil the comfort criteria in the most demanding curve and curve transition. Instead, an enhanced approach is

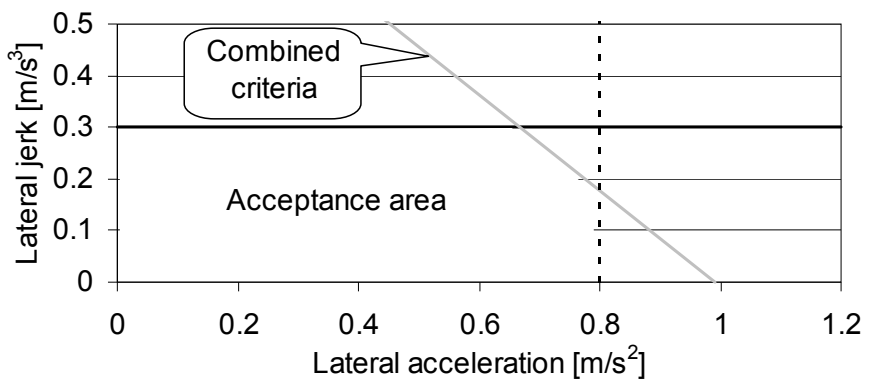

Figure 2: Comfort acceptance area as a function of lateral acceleration and jerk. 


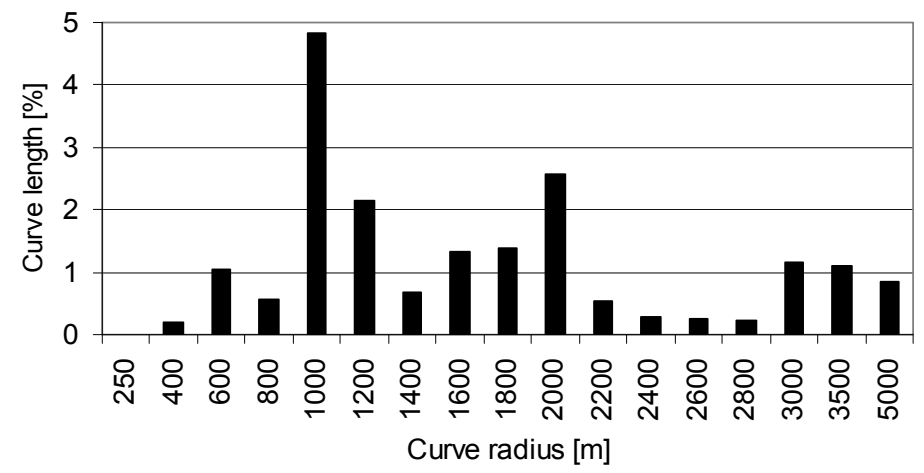

Figure 3: Distribution of circular curves (curve transitions excluded) with radii less than $6000 \mathrm{~m}$ as a function of the total length of the Stockholm-Gothenburg line.

suggested, where the amount of tilt depends on local track conditions and the train speed. Such a solution is possible with computer-controlled actuators, route files (defining track alignment and applied cant) stored onboard, and train positioning systems.

The present paper uses the Swedish mainline between Stockholm and Gothenburg as an example. The track may be characterized by the curve distribution, which can be expressed as a percentage of the total length of the track. The curve radius indicated is the mean radius in a group, e.g. the curves in the $1000 \mathrm{~m}$ group range from 900 to $1100 \mathrm{~m}$. The Stockholm-Gothenburg line has a variety of curves ranging from $352 \mathrm{~m}$ radius and up. The curve distribution for the line is shown in Figure 3. The total length of the circular curves (transition curves are excluded) with radii less than $6000 \mathrm{~m}$ constitutes $19 \%$ of the line. The total length of the line is $457 \mathrm{~km}$.

Applying a motion sickness dose perspective on a railway line is an interesting approach [17]. This means that the risk of motion sickness is estimated as a function of time. The influence of different tilt algorithms and speed profiles may be quantified as motion sickness doses by means of the following process: The train speeds at each point on the line are simulated in an Excel-based simulation program. These simulated train speeds are used as input to quasi-static motion calculations, according to [11]. The calculated motions are then accumulated over time to give motion sickness doses.

\subsection{Today's speed profiles}

Today's Swedish speed profiles for tilting trains are set by allowing maximum $1.60 \mathrm{~m} / \mathrm{s}^{2}$ track plane acceleration and $0.52 \mathrm{~m} / \mathrm{s}^{3}$ maximum rate of change of track plane acceleration. Today's tilt control applies a fixed ratio between track plane acceleration and tilt angle, which gives about $0.60 \mathrm{~m} / \mathrm{s}^{2}$ lateral acceleration perceived by the passengers at maximum track plane acceleration and about 
$0.20 \mathrm{~m} / \mathrm{s}^{3}$ lateral jerk perceived by the passengers at maximum rate of change of track plane acceleration. These passenger comfort values are slightly better than what could be accepted according to the comfort criteria in Figure 2. The difference may be used to reduce the risk of motion sickness. The following three control possibilities can be distinguished:

1. Original control, fix ratio between tilt angle and track plane acceleration

2. As 1, but with reduced ratio that just meets the comfort criteria

3. Optimized control on a curve by curve basis that just meets the comfort criteria.

The effects on certain motion components of the different control possibilities are shown in Table 1. The table contains data for three curves and their transitions. The original control always applies tilt in proportion to the track plane acceleration, while the optimized control considers each curve separately. The first curve has a rather large radius and there is no need to tilt at all; the

Table 1: $\quad$ Motion components in selected curves.

\begin{tabular}{|c|c|c|c|c|c|c|c|c|}
\hline \multicolumn{3}{|c|}{ Track data } & \multicolumn{3}{|c|}{ Original control } & \multicolumn{3}{|c|}{ Optimized control } \\
\hline Element & Radii [m] & Cant [mm] & $\ddot{y} \quad\left[\mathrm{~m} / \mathrm{s}^{2}\right]$ & $\ddot{z} \quad\left[\mathrm{~m} / \mathrm{s}^{2}\right] \dot{\varphi}$ & {$[\mathrm{deg} / \mathrm{s}]$} & $\ddot{y} \quad\left[\mathrm{~m} / \mathrm{s}^{2}\right]$ & $\ddot{z} \quad\left[\mathrm{~m} / \mathrm{s}^{2}\right] \dot{\varphi}$ & {$[\mathrm{deg} / \mathrm{s}]$} \\
\hline $\begin{array}{c}\text { Transition } \\
\text { Circular }\end{array}$ & 5440 & 25 & 0.11 & 0.010 & 2.0 & 0.30 & 0.006 & 1.0 \\
\hline Transition & & & & & 2.0 & & & 1.0 \\
\hline $\begin{array}{c}\text { Transition } \\
\text { Circular } \\
\text { Trancition }\end{array}$ & 1401 & 125 & 0.36 & 0.154 & 3.7 & 0.67 & 0.138 & 2.9 \\
\hline$\frac{\text { Transition }}{\text { Transition }}$ & & & & & $\begin{array}{l}3.4 \\
2.3\end{array}$ & & & $\begin{array}{l}2.6 \\
2.0\end{array}$ \\
\hline $\begin{array}{l}\text { Circular } \\
\text { Transition }\end{array}$ & 998 & 140 & 0.60 & 0.297 & 2.3 & 0.80 & 0.283 & 2.0 \\
\hline
\end{tabular}

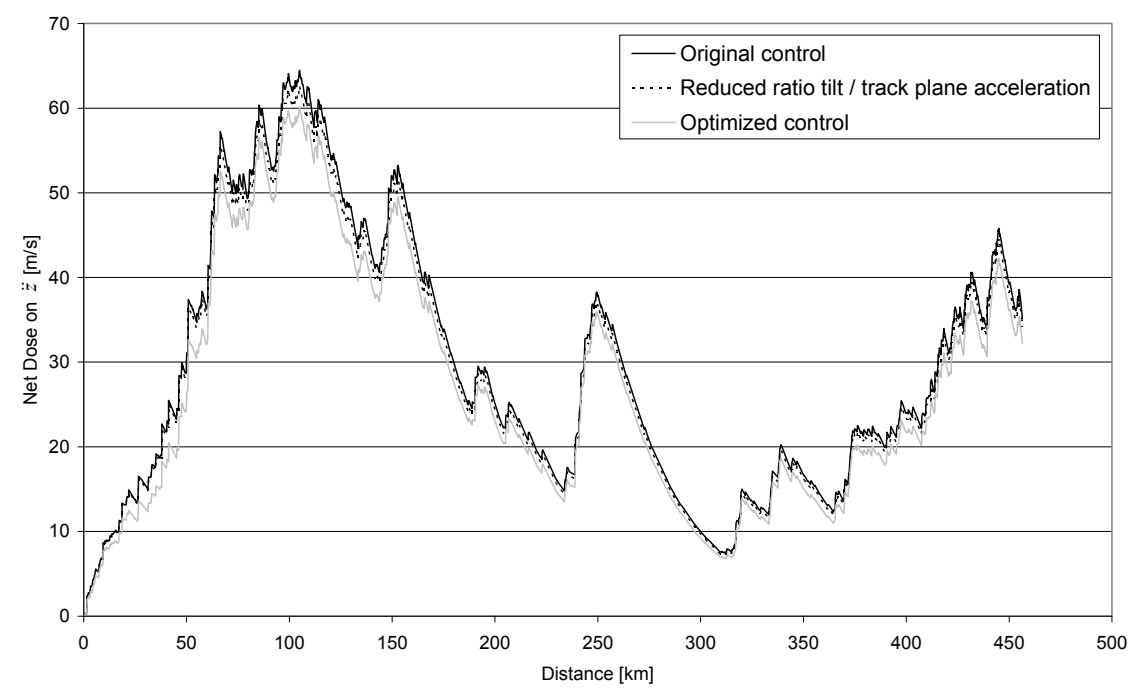

Figure 4: Net Dose on carbody vertical acceleration for today's speed profile. 
carbody roll motion in the case of the optimized control is purely a result of the applied cant. The second curve has fairly short transitions making the combination of lateral acceleration and jerk decisive as regards the need for tilt. The third curve is close to the permitted track plane acceleration; considerable tilt must be applied to satisfy the lateral acceleration requirements. All three curves are examples where a lower tilt angle could be applied to reduce the carbody vertical acceleration and the carbody roll velocity without compromising the set comfort criteria.

As mentioned in Section 3.3, motion sickness is not an effect of one or a few curves, but rather an accumulated effect of several curves. The Net Dose method both takes this and recovery during periods with fewer motions into account. Figure 4 shows the Net Dose calculated on carbody vertical acceleration for the Stockholm-Gothenburg line.

The difference in Net Dose on carbody vertical acceleration may look small, but the case with reduced ratio between tilt angle and track plane acceleration gave a significant positive effect on the risk of motion sickness in an on-track test [7]. The optimized control gives about twice as large a reduction of the maximum Net Dose calculated on vertical acceleration as in the on-track test.

\subsection{Improved speed profiles}

Another objective of the present study is to reduce the running time without increasing the risk of motion sickness. About 9\% running time may be saved if trains and speed profiles are improved [18]. Maintaining the original control would not only require a larger maximum tilt angle, but would also result in an increased risk of motion sickness. The present study shows that the maximum Net Dose value of carbody vertical acceleration will increase by $26 \%$ if the tilt control is kept as today. The following control possibilities are available to maintain the maximum Net Dose value of vertical acceleration as today with the improved speed profile:

- $\quad$ Reduced ratio between tilt angle and track plane acceleration. This will cause the maximum lateral acceleration perceived by passengers to increase to $1.5 \mathrm{~m} / \mathrm{s}^{2}$ and the maximum lateral jerk to increase to $0.6 \mathrm{~m} / \mathrm{s}^{3}$.

- Optimized control on a curve by curve basis. The values become $1.4 \mathrm{~m} / \mathrm{s}^{2}$ and $0.5 \mathrm{~m} / \mathrm{s}^{3}$ respectively.

None of the options above are attractive, as comfort would be dramatically reduced compared with today's tilt control.

\section{Speed profiles as a tool to minimize motion sickness risk}

The optimized tilt control was thus found to be unable to combine good comfort and low risk of motion sickness for the improved speed profile. This is a consequence of the maximized speed profile, as full tilt must be applied in many curves. One possibility to regain some scope or the optimized control is to reduce the speed again. This contradicts the purpose of using the improved speed 
profile, but the impact on running time may be small if speed is reduced only at selected locations. The following control options are available to maintain the same maximum Net Dose on carbody vertical acceleration as today if $8 \%$ running time savings are accepted.

- $\quad$ Reduced ratio between tilt angle and track plane acceleration. This will result in a maximum lateral acceleration perceived by passengers of $1.1 \mathrm{~m} / \mathrm{s}^{2}$ and a maximum lateral jerk of $0.4 \mathrm{~m} / \mathrm{s}^{3}$.

- Optimized control on a curve by curve basis to just satisfy the comfort criteria in Figure 2. The maximum lateral acceleration and jerk become $0.8 \mathrm{~m} / \mathrm{s}^{2}$ and $0.3 \mathrm{~m} / \mathrm{s}^{3}$ respectively.

These options look much more attractive from a passenger comfort perspective, but at the expense of $1 \%$ lost running time. The largest reduction of maximum Net Dose is obtained where the Dose takes its largest values. Figure 5 shows one example with a speed reduction from $190 \mathrm{~km} / \mathrm{h}$ to $180 \mathrm{~km} / \mathrm{h}$ between kilometre 60 and 115 on the Stockholm-Gothenburg line.

\section{Discussion and conclusions}

The Net Dose calculations in the present paper are based on carbody vertical acceleration, as this was the motion component that showed the best correlation to the risk of motion sickness [10]. Using carbody roll velocity instead of vertical acceleration would shift the focus from circular curves to transitions, but the track sections with the largest risk of motion sickness remain the same. It could also be discussed whether quasi-static motion calculation is suitable. Support for

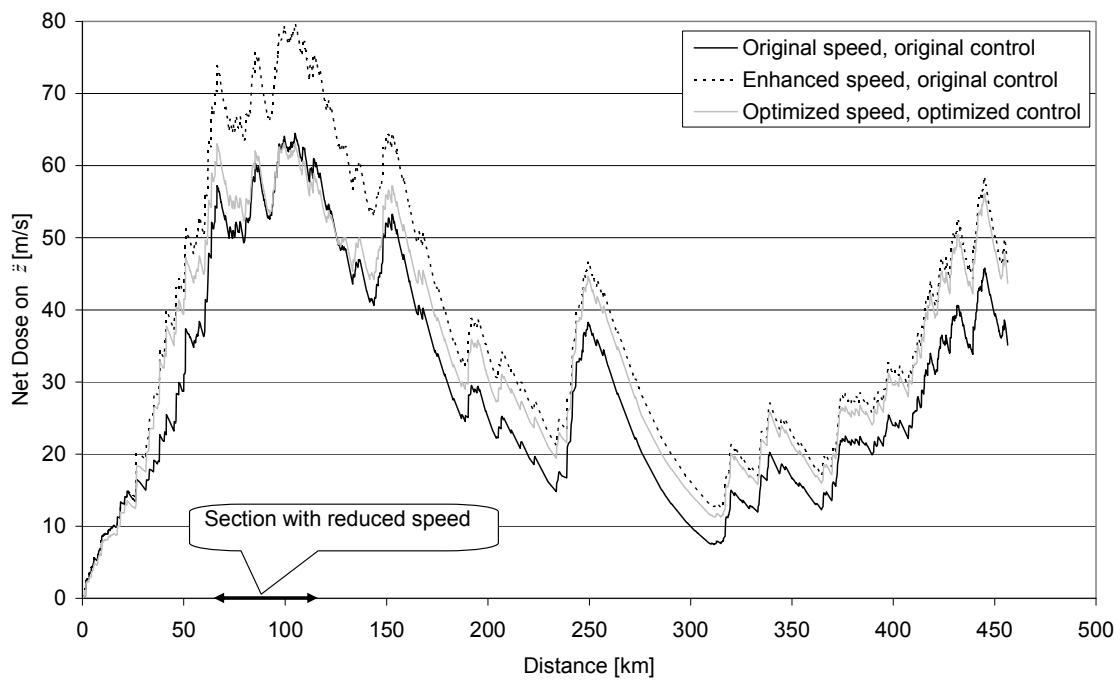

Figure 5: Net Dose on carbody vertical acceleration for the improved speed profile. 
doing so can be found in [11] and [19]; the latter indicates that weighting of carbody vertical acceleration to the risk of motion sickness must be extended towards quasi-static motions.

The present paper presents tilt algorithms aimed at balancing the conflicting objectives of ride comfort and less risk of motion sickness. An enhanced approach is taken, where the amount of tilt depends on local track conditions and train speed. The enhanced approach proved to be effective as long as partial tilt could be applied in the majority of the curves and still satisfy the comfort criteria. Local speed reductions were found to be effective for regaining useful scope work area for the enhanced approach, but at the expense of lost running time.

\section{Acknowledgements}

The financial support from the Swedish Governmental Agency for Innovation Systems (VINNOVA) and the Swedish National Rail Administration (Banverket) is gratefully acknowledged. The authors thank Bombardier Transportation for permission to publish this paper.

\section{References}

[1] Kufver, B. \& Persson, R. On enhanced tilt strategies for tilting trains. Proc. of Comprail 2006, CMP/WIT Press: Southampton, pp. 839-848. ISBN 184564-177-9.

[2] Deischl, WVV. Linienverbesserungen oder gesteuerte Achsen? Verkehrstechnische Woche, 31(9), pp. 97-108, 1937.

[3] Van Dorn, W. \& Beemer, P. Suspension for vehicles. US Patent 2.225.242, 1938.

[4] Persson R., Goodall R. \& Sasaki K. Carbody Tilting - Technologies and Benefits. Proceedings of the 21st IAVSD Symposium, Vehicle System Dynamics, Volume 47, No 8, pp. 949-981, 2009

[5] Hughes, M. Tilt nausea is bad business. Railway Gazette International, 153(4), p. 249, 1997.

[6] Cléon LM., Quetin F., Thibedore T. \& Griffin M. Research on motion sickness. Proc. of World Congress on Railway Research 1999, Tokyo.

[7] Förstberg, J. Ride comfort and motion sickness in tilting trains - Human responses to motion environments in train and simulator experiments. $\mathrm{PhD}$ thesis, TRITA-FKT Report 2000:28, KTH, Stockholm.

[8] Brume, M. Why are Pendolinos so nauseating? Rail Professional, 93, p. 5, 2004.

[9] Ohno, H. What aspect is needed for a better understanding of tilt sickness? Quarterly Report of RTRI, Volume 37. pp. 9-13, Japan, 1996.

[10] Persson, R. Motion sickness in tilting trains - Description and analysis of the present knowledge. ISBN 978-91-7178-680-3. KTH, Stockholm, 2008. 
[11] UIC. Competitive and sustainable growth programme, Fast and Comfortable Trains (FACT), Track for tilting trains - Report D8. http://www.uic.org/download.php/fact/d8.pdf.

[12] Urabe, S., Koyama, M. \& Iwase, Y. Evaluations of train riding comfort under various speeds at curves. Quarterly report of RTRI. Volume 7. No 2. pp. 34-36, 1966.

[13] Suzuki, H. Recent research and developments in the field of riding comfort evaluation. Quarterly report of RTRI. Volume 37. pp. 4-8, Japan, 1996.

[14] Suzuki, H., Shiroto, H., Tanka, A., Tezuka, K. \& Takai, H. Psychophysical evaluation of railway vibration discomfort on curved sections. Quarterly report of RTRI. Volume 41. pp. 106-111, Japan, 2000.

[15] Harborough, PR. Passenger comfort during high speed curving - analysis and conclusions, BRR TR DOS 017, British Rail Research: Derby, 1986.

[16] CEN. Railway applications - Ride comfort for passengers - Measurements and evaluation, EN 12299. CEN. Brussels, 2009.

[17] Kufver, B. \& Förstberg, J. A net dose model for development of nausea. Proc. of $34^{\text {th }}$ meeting of the UK Group on Human Response to Vibration, Dunton, Essex, England, 1999.

[18] Persson, R. Tilting trains - technology, benefits and motion sickness. Licentiate Thesis. ISBN 978-91-7178-972-3. KTH, Stockholm, 2008.

[19] Persson, R. Weighting curves to motion sickness. Proc. of $44^{\text {th }}$ meeting of the UK Group on Human Response to Vibration, Loughborough, England, 2009. 